\title{
Efficacy and safety profile of xanthines in COPD: a network meta-analysis
}

\author{
Mario Cazzola, Luigino Calzetta ${ }^{1}$, Peter J. Barnes², Gerard J. Criner ${ }^{3}$, \\ Fernando J. Martinez ${ }^{4}$, Alberto Papi ${ }^{5}$ and Maria Gabriella Matera ${ }^{6}$
}

Affiliations: 'Dept of Experimental Medicine and Surgery, University of Rome Tor Vergata, Rome, Italy. ${ }^{2}$ Airway Disease Section, National Heart and Lung Institute, Imperial College, London, UK. ${ }^{3}$ Dept of Thoracic Medicine and Surgery, Temple Lung Center, Lewis Katz School of Medicine at Temple University, Philadelphia, PA, USA. ${ }^{4}$ Joan and Sanford I. Weill Dept of Medicine, Weill Cornell Medical College, New York Presbyterian Hospital/Weill Cornell Medical Center, New York, NY, USA. ${ }^{5}$ Dept of Internal and Cardiorespiratory Medicine, Research Center on Asthma and COPD, University of Ferrara, Ferrara, Italy. ${ }^{6}$ Dept of Experimental Medicine, Unit of Pharmacology, University of Campania Luigi Vanvitelli, Naples, Italy.

Correspondence: Luigino Calzetta, Dept of Experimental Medicine and Surgery, Via Montpellier 1, 00133 Rome, Italy. E-mail: luigino.calzettaduniroma2.it.

@ERSpublications

Doxofylline is an effective and safe xanthine for the treatment of COPD http://ow.ly/ApV330iXSXv

Cite this article as: Cazzola M, Calzetta L, Barnes PJ, et al. Efficacy and safety profile of xanthines in COPD: a network meta-analysis. Eur Respir Rev 2018; 27: 180010 [https://doi.org/10.1183/16000617.0010-2018].

ABSTRACT Theophylline can still have a role in the management of stable chronic obstructive pulmonary disease (COPD), but its use remains controversial, mainly due to its narrow therapeutic window. Doxofylline, another xanthine, is an effective bronchodilator and displays a better safety profile than theophylline. Therefore, we performed a quantitative synthesis to compare the efficacy and safety profile of different xanthines in COPD.

The primary end-point of this meta-analysis was the impact of xanthines on lung function. In addition, we assessed the risk of adverse events by normalising data on safety as a function of person-weeks. Data obtained from 998 COPD patients were selected from 14 studies and meta-analysed using a network approach.

The combined surface under the cumulative ranking curve (SUCRA) analysis of efficacy (change from baseline in forced expiratory volume in $1 \mathrm{~s}$ ) and safety (risk of adverse events) showed that doxofylline was superior to aminophylline (comparable efficacy and significantly better safety), bamiphylline (significantly better efficacy and comparable safety), and theophylline (comparable efficacy and significantly better safety).

Considering the overall efficacy/safety profile of the investigated agents, the results of this quantitative synthesis suggest that doxofylline seems to be the best xanthine for the treatment of COPD.

\section{Introduction}

Theophylline is one of the most widely prescribed drugs worldwide for the treatment of chronic obstructive pulmonary disease (COPD), not only because it is inexpensive and widely available, but also because it may benefit patients with COPD [1]. In fact, it improves both trough and peak forced expiratory volume in $1 \mathrm{~s}(\mathrm{FEV} 1)$ and forced vital capacity in clinically stable COPD patients [2]. Furthermore, it is able to increase exercise tolerance [3,4], probably because it reduces air trapping, suggesting an effect on peripheral airways [5], and this may explain why some patients with COPD may obtain considerable symptomatic improvement without any increase in spirometric values [6]. In patients

This article has supplementary material available from err.ersjournals.com

Received: Feb 012018 | Accepted after revision: March 112018

Provenance: Submitted article, peer reviewed.

Copyright CERS 2018. ERR articles are open access and distributed under the terms of the Creative Commons Attribution Non-Commercial Licence 4.0 
with severe COPD, withdrawal of theophylline causes significant clinical deterioration despite therapy with other bronchodilators, indicating its added value [7]. Besides, compared with placebo, theophylline seems more effective over 12 months at reducing the frequency and duration of acute COPD exacerbations [8]. In addition, the use of theophylline leads to effects such as anti-inflammatory activity and improved diaphragm contractility, but their clinical relevance has not been firmly established [1].

Therefore, theophylline can have a role in the management of stable COPD [1]. However, recommendations for treating COPD with theophylline vary across national guidelines [9], probably because there are many controversies about its use [10], as it is less effective and well tolerated than inhaled long-acting bronchodilators and inhaled corticosteroids have a greater anti-inflammatory effect [1]. In most treatment guidelines, theophylline is relegated to second- or third-line therapy because of its narrow therapeutic window and propensity for pharmacological interactions [10], which makes its use challenging, especially in elderly patients with comorbidities receiving multiple classes of drug. Moreover, a recent meta-analysis of seven observational studies has suggested that theophylline slightly increases all-cause death in COPD patients [11].

Several other xanthines, such as aminophylline, bamiphylline and doxofylline, have been synthesised to be used clinically in various parts of the world for the treatment of respiratory disease, with the anticipation that such drugs would have greater efficacy than theophylline, but with improved side-effect profiles because of their different pharmacological profiles (table 1).

There is evidence that doxofylline, at least, is an effective bronchodilator for relieving airway obstruction and displays a better safety profile than theophylline, having a favourable risk-to-benefit ratio [12-14]. These findings suggest that it could be an attractive alternative to theophylline in the treatment of patients with COPD. However, doxofylline is not included in any guideline for management of COPD, probably also because most trials of doxofylline in people with COPD have used small numbers of participants. Undoubtedly, there is an evident dichotomy between the safety and efficacy profile of doxofylline that arises from clinical trials and positioning of this oral xanthine in the treatment of COPD.

Given the number of xanthines available for COPD and the absence of clinical trials that have directly compared all relevant agents, we performed a systematic review and network meta-analysis of randomised and nonrandomised clinical trials with the aim of evaluating their comparative efficacy and safety in patients with stable COPD.

\section{Materials and methods \\ Search strategy}

This network meta-analysis has been registered at PROSPERO (www.crd.york.ac.uk/PROSPERO identifier number CRD42017077901), and performed in agreement with the Preferred Reporting Items for Systematic Reviews and Meta-Analyses (PRISMA) statement (figure S1A) [15]. This quantitative synthesis satisfied all the recommended items reported by the PRISMA-P 2015 checklist [16].

Two reviewers (MC and LC) performed a comprehensive literature search for clinical studies evaluating the influence of xanthines in COPD patients. The PICO (patient problem, intervention, comparison and outcome) framework was used to develop the literature search strategy, as previously described [17].

TABLE 1 Main pharmacological characteristics of the xanthines investigated in this quantitative synthesis

\begin{tabular}{|c|c|c|c|c|}
\hline & $\begin{array}{l}\text { Adenosine receptors } \\
\text { lantagonism, affinityl }\end{array}$ & $\begin{array}{l}\text { PDE (inhibitory } \\
\text { potencyl }\end{array}$ & $\begin{array}{c}\mathrm{PI}_{3} \text { kinase } \\
\text { (inhibitory potency) }\end{array}$ & $\begin{array}{l}\text { HDAC (inhibitory } \\
\text { potency) }\end{array}$ \\
\hline Bamiphylline & $A_{1} / A_{2} 562$-fold & NA & NA & NA \\
\hline Enprophylline & $\begin{array}{c}A_{1} 42-156 \mu \mathrm{M} \\
A_{2 A} 38-81 \mu \mathrm{M} \\
A_{2 B} 5-20 \mu \mathrm{M} \\
A_{3} 65-93 \mu \mathrm{M}\end{array}$ & $\begin{array}{l}\text { PDE1-5 > } 100 \mu \mathrm{M} \\
\text { (modest effect) }\end{array}$ & NA & NA \\
\hline $\begin{array}{l}\text { Theophylline and aminophylline } \\
\text { (theophylline ethylenediamine) }\end{array}$ & $\begin{array}{c}\mathrm{A}_{1} 10-30 \mu \mathrm{M} \\
\mathrm{A}_{2 \mathrm{~A}} 2-10 \mu \mathrm{M} \\
\mathrm{A}_{2 \mathrm{~B}} 10-30 \mu \mathrm{M} \\
\mathrm{A}_{3} 20-100 \mu \mathrm{M}\end{array}$ & $\begin{array}{l}\text { PDE3 } 98 \mu \mathrm{M} \\
\text { PDE4 } 150 \mu \mathrm{M}\end{array}$ & $100 \mu \mathrm{M}$ & $\begin{array}{l}\text { HDAC1-11 no } \\
\text { effect }\end{array}$ \\
\hline
\end{tabular}

PDE: phosphodiesterase; $\mathrm{PI}_{3}$ : phosphoinositide-3; HDAC: histone deacetylase; NA: not available. 
Namely, the "patient problem" included subject affected by stable COPD; the "intervention" regarded the administration of different xanthines; the effect of placebo and/or the values at baseline in clinical trials were used as "control"; and the assessed "outcomes" were the lung function, risk of adverse events, the therapeutic efficacy and dyspnoea. Thus, the terms aminophylline, bamiphylline, doxofylline, enprophylline and theophylline were searched for the drugs, and the terms chronic obstructive pulmonary disease or COPD were searched for the disease. The main pharmacological characteristics of the xanthines investigated in this quantitative synthesis are reported in table 1.

The search was performed in the Cochrane Central Register of Controlled Trials (CENTRAL), MEDLINE, Embase, Scopus, Google Scholar, Web of Science and ClinicalTrials.gov databases through February 2018, in order to provide for relevant studies available up to February 27, 2018. No language restriction was applied.

The clinical trials reporting the efficacy and/or safety profile of xanthines in COPD patients were searched in agreement with the following query translation: ["pulmonary disease, chronic obstructive"[medical subject heading $(\mathrm{MeSH})$ terms] OR ("pulmonary"[All Fields] AND "disease"[All Fields] AND "chronic"[All Fields] AND "obstructive"[All Fields]) OR "chronic obstructive pulmonary disease"[All Fields] OR "copd"[All Fields]) AND (("bamiphylline"[Supplementary Concept] OR "bamiphylline"[All Fields]) OR ("enprophylline”[Supplementary Concept] OR "enprophylline”[All Fields]) OR (“doxofylline”[Supplementary Concept] OR “doxofylline”[All Fields]) OR (“theophylline”[MeSH Terms] OR "theophylline”[All Fields]) OR ("aminophylline”[MeSH Terms] OR “aminophylline”[All Fields]))].

\section{Study selection}

Published and unpublished clinical trials (both randomised and non-randomised) involving COPD patients and reporting the direct comparison between at least two different xanthines with regard to the efficacy and/or safety profile were included in this network meta-analysis.

Clinical trials reporting no direct comparison across xanthines, those not reporting data on efficacy and/or safety profile, and those available exclusively as abstracts were excluded by this network meta-analysis synthesis. Furthermore, nonclinical trials were excluded by this quantitative synthesis.

Two reviewers (MC and LC) independently checked the relevant studies identified from literature searches obtained from the abovementioned databases. The studies were selected in agreement with the abovementioned criteria, and any difference in opinion about eligibility was resolved by general consensus.

\section{Quality score, risk of bias and evidence profile}

The Jadad score, with a scale of 1-5 (score of 5 being the best quality), was used to assess the quality of the clinical trials concerning the likelihood of biases related to randomisation, double blinding, withdrawals and dropouts [18]. A Jadad score $\geqslant 3$ was defined to identify high-quality studies. Two reviewers independently assessed the quality of individual studies, and any difference in opinion about the quality score was resolved by consensus.

The risk of bias for the impact of xanthines on lung function and their safety profile in stable COPD patients was assessed via the consistency/inconsistency analysis to check whether the outcomes resulting from the consistency and inconsistency models fit adequately with the line of equality, as previously described [19]. Furthermore, the inconsistency of evidence was also assessed by quantifying the inconsistency factor, indicating whether one of the treatment had a different effect when it was compared with the others [20].

Meta-regression analysis was performed to examine the source of heterogeneity between studies and identify potential confounder covariates specifically for the impact of xanthines on lung function and the risk of adverse events [19].

The quality of the evidence concerning the impact of xanthines on lung function and the risk of adverse events was assessed in agreement with the grading of recommendations assessment, development and evaluation (GRADE) system [21].

\section{Data extraction}

Data from included studies were extracted and checked for study characteristics and duration, doses of xanthines, concomitant medications, disease characteristics, ethnicity, age, sex, lung function, safety, therapeutic efficacy, dyspnoea and Jadad score. Due to the complexity of this meta-analysis, data have been extracted in agreement with data extraction for complex meta-analysis (DECiMAL) recommendations [22]. 


\section{End-points}

The primary end-point of this meta-analysis was the impact of different xanthines on the change from baselines in FEV1.

The secondary end-point were the risk of adverse events, via normalising the data on safety as a function of person-weeks, therapeutic efficacy (the rate of patients that achieved the 3rd or 4th rank in a four-point nonvalidated scale, or that achieved the 2 nd or $3 \mathrm{rd}$ rank in a three-point nonvalidated scale, where the higher values represented greater therapeutic efficacy [23-27]) and the change from baseline in dyspnoea via the Medical Research Council scale [28] or a nonvalidated dyspnoea score that assessed dyspnoea using a four-point scale $[29,30]$. More details concerning the scales used to assess the therapeutic efficacy and dyspnoea are reported in table S1.

\section{Data analysis}

This network meta-analysis was performed to compare the impact of specific xanthines in COPD patients by analysing the data extracted from studies that directly compared at least two different xanthines. Results are expressed as relative effect and 95\% credible interval (95\% CrI).

A full Bayesian evidence network was used (chains: 4; initial values scaling: 2.5; tuning iterations: 20000; simulation iterations: 50000; tuning interval: 10), and the convergence diagnostics for consistency and inconsistency was assessed via the Brooks-Gelman-Rubin method, as previously reported [31].

Due to the characteristics of parameters besides the available data, the noninformative distributions specified the prior densities, in agreement with the Bayesian approaches to clinical trials and healthcare evaluation $[32,33]$. Since the distributions were sufficiently vague, the reference treatment, study baseline effects and heterogeneity variance were unlikely to have a noticeable impact on model results. In this condition, GeMTC software automatically generates and runs the required Bayesian hierarchical model and selects the prior distributions and starting values as well, via heuristically determining a value for the outcome scale parameter (i.e. outcome scale S) $[34,35]$. The posterior mean deviance of data points in the unrelated mean effects model were plotted against their posterior mean deviance in the consistency model in order to provide information for identifying the loops in the treatment network where evidence was inconsistent [36].

The efficacy/safety profile was assessed by plotting the summary findings regarding the relative efficacy and safety of specific xanthines comparisons, as previously described [37]. Furthermore, the probability that each intervention arm was the most effective than the others was calculated by counting the proportion of iterations of the chain in which each intervention arm had the highest mean difference, and the surface under the cumulative ranking curve (SUCRA), representing the summary of these probabilities, was also calculated. The SUCRA is $100 \%$ when a treatment is certain to be the best, and $0 \%$ when a treatment is certain to be the worst $[31,38]$.

A pooled analysis was performed to calculate the frequency of adverse events, ranked in agreement with the European Medicine Agency undesirable effects (section 4.8), as follows. Very common: $\geqslant 1 / 10$; common $\geqslant 1 / 100$ to $<1 / 10$; uncommon $\geqslant 1 / 1000$ to $<1 / 100$; frequency not known if not calculable from the available data (www.ema.europa.eu/docs/en_GB/document_library/Presentation/2013/01/WC500137021. pdf). The overall adverse events frequency and the frequency of specific adverse events were compared across the investigated drugs.

OpenMetaAnalyst [39] and GeMTC [34] software were used for performing the network meta-analysis and meta-regression, OpenEpi [40] software for the pooled analysis, GraphPad Prism (La Jolla, CA, USA) software to graph the data, and GRADEpro software to assess the quality of evidence [21]. Statistical significance was considered to be $\mathrm{p}<0.05$.

\section{Results}

\section{Study characteristics}

Data obtained from 998 COPD patients $(47.94 \%$ treated with doxofylline, $24.82 \%$ treated with theophylline, $21.71 \%$ treated with aminophylline and 5.53\% treated with bamiphylline) were selected from 14 studies [23-27, 29, 30, 41-47] published between 1987 and 2016. The relevant studies and patients' characteristics are described in table S2, and figure S1B shows the network across the xanthines involved in the Bayesian analysis.

All the meta-analysed clinical trials were published as full-text papers [23-27, 29, 30, 41-47]. Four studies had a Jadad score $\geqslant 3[23,24,42,45,47]$, and 10 studies had a Jadad score $\geqslant 1$ and $<3[25-27,29,30,41$, $43,44,46,47]$. The length of treatment ranged from 1 day to 12 weeks. 


\section{Network meta-analysis}

Primary end-point

No significant differences were detected with regard to the change from baseline in FEV1 across aminophylline, doxofylline, and theophylline. The subset analysis of the studies that expressed the change from baseline in FEV1 as volume ( $\mathrm{mL}$ or $\mathrm{L}$ ) indicated that theophylline increased FEV1 by 12.0 (95\% CrI -142.5-173.7) $\mathrm{mL}$ versus doxofylline and 69.6 (95\% CrI -211.6-348.2) $\mathrm{mL}$ versus aminophylline, and that doxofylline increased FEV1 by 55.4 (95\% CrI -212.5-310.5) $\mathrm{mL}$ versus aminophylline. In contrast, aminophylline, doxofylline and theophylline were both significantly $(p<0.001)$ more effective than bamiphylline (figure 1a). Specifically, aminophylline, doxofylline and theophylline increased FEV1 by 538.1 (95\% CrI 122.6 -850.7) mL, 593.5 (95\% CrI 271.1-791.6) $\mathrm{mL}$ and 604.3 (95\% CrI 246.2-846.1) mL, respectively, versus bamiphylline $(\mathrm{p}<0.001)$.

\section{Secondary end-points}

Doxofylline was significantly $(\mathrm{p}<0.001)$ safer than both aminophylline and theophylline, whereas no difference resulted versus bamiphylline. No significant differences were detected with regard to the risk of adverse events across aminophylline, bamiphylline and theophylline (figure $1 \mathrm{~b}$ ).

When coupling relative effects for efficacy and safety, doxofylline appeared to be superior to aminophylline (comparable efficacy and significantly better safety), bamiphylline (significantly better efficacy and comparable safety) and theophylline (comparable efficacy and significantly better safety), as shown by the efficacy/safety analysis reported in figure $2 \mathrm{a}$. The superiority of doxofylline over aminophylline, bamiphylline and theophylline was further confirmed by the combined efficacy/safety SUCRA analysis (figure $2 b$ ).

The SUCRA analysis also indicated that doxofylline was the most effective xanthine with regard to the impact on therapeutic efficacy (SUCRA value 0.71), followed by aminophylline (SUCRA value 0.49) and theophylline (SUCRA value 0.31). Doxofylline and aminophylline both elicited a greater beneficial impact on the improvement of dyspnoea score (SUCRA values 0.75 and 0.71 , respectively), compared with theophylline (SUCRA value 0.04).

\section{Pooled analysis of safety profile}

The overall pooled analysis of the safety profile showed that the frequency of adverse events detected in COPD patients treated with doxofylline $(22.0 \%)$ was significantly $(\mathrm{p}<0.001)$ lower than that found for both theophylline (61.7\%) and aminophylline (54.55\%).

The analysis of specific adverse events is reported in table 2, and showed that the most frequent adverse events were correlated with the administration of aminophylline (palpitations $12.73 \%$, gastrointestinal discomfort $11.82 \%$ and insomnia 9.09\%) and theophylline (nausea $10.8 \%$, epigastralgia $9.1 \%$, headache $8.6 \%$ and dyspepsia $7.3 \%$ ). Generally, the frequency of specific adverse events induced by doxofylline was significantly $(\mathrm{p}<0.05)$ lower than that detected for both theophylline and aminophylline. The pooled analysis was not performed on bamiphylline since no data were available concerning the specific adverse events.

The percentage of patients that withdrew from the clinical trials due to adverse events was significantly $(\mathrm{p}<0.001)$ higher in the subjects treated with theophylline $(10.0 \%)$ compared with those treated with doxofylline (2.6\%). Overall, the reported adverse events that led to study discontinuation were dyspepsia, epigastralgia, nausea and palpitations. No data are available concerning the withdrawal due to adverse events for the other investigated xanthines.

\section{Bias and quality of evidence}

The analysis of inconsistency showed that no significant discrepancy exists between direct and indirect evidences for both efficacy (inconsistency factor $-0.05,95 \%$ CrI $-0.64-0.69 ; \mathrm{p} \geqslant 0.05$ ) and safety profile (inconsistency factor $-1.39,95 \%$ CrI $-4.69-0.73 ; \mathrm{p} \geqslant 0.05$ ). The consistency/inconsistency analysis indicated that all points fit adequately with the line of equality (efficacy $\mathrm{R}^{2} 0.99$, slope $0.99,95 \%$ CI 0.92 1.07; safety: $\mathrm{R}^{2} 0.95$, slope $1.26,95 \%$ CI $0.86-1.66$ ) (figure S2).

The meta-regression model of the effect estimates resulting for FEV1 indicated that neither the total dose (study duration $\times$ daily dose) of xanthines administered to COPD patients during the studies, nor the route of administration, lung function, ethnicity and Jadad score were significant $(p>0.05)$ confounder variables that may have altered the results of this meta-analysis. The meta-regression model of the effect estimates resulting for adverse events indicated that neither lung function, nor ethnicity and Jadad score represented effect modifiers. Conversely, the total dose of xanthines administered during the studies (coefficient $-0.08, \mathrm{p}<0.001$ ) and the route of administration (oral versus i.v. coefficient 1.41, $\mathrm{p}<0.001$ ) were significant confounding factors for the frequency of adverse events (figure S3). 
a)

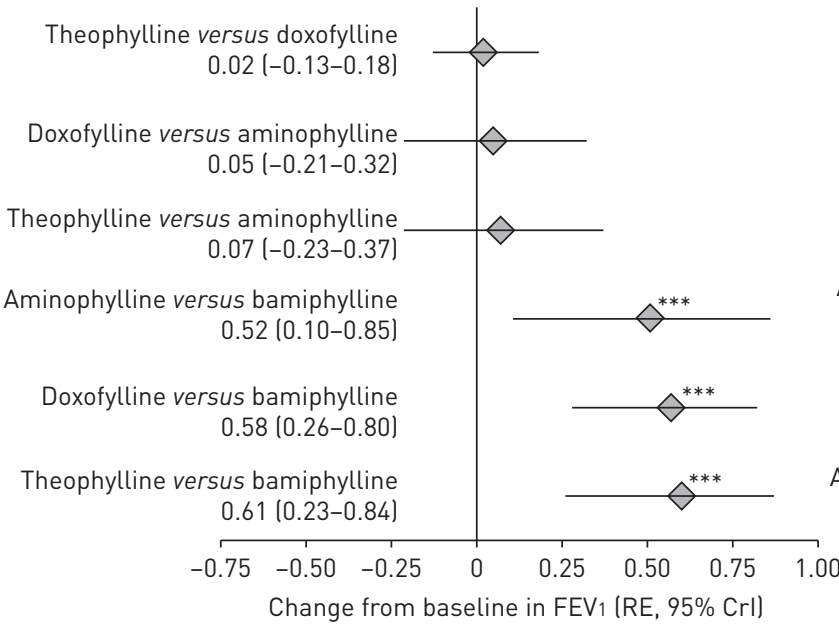

b)

Doxofylline versus aminophylline $0.17(0.07-0.44)$

Doxofylline versus theophylline $0.38(0.18-0.68)$

Doxofylline versus bamiphylline $1.04(0.02-48)$

Aminophylline versus theophylline $2.20(0.72-7.28)$

Theophylline versus bamiphylline $2.82(0.04-145)$

Aminophylline versus bamiphylline $6.32(0.09-340)$

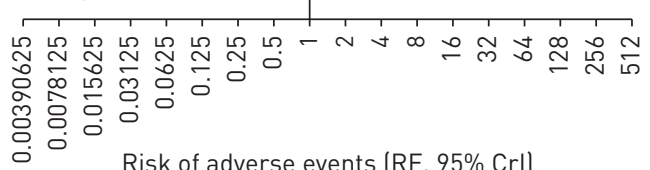

FIGURE 1 Impact of xanthines on change from baselines in a) forced expiratory volume in $1 \mathrm{~s}$ (FEV1) and b) the risk of adverse events. RE: relative effect; Crl: credible interval. ${ }^{* *}: \mathrm{p}<0.001$ versus comparators.

The GRADE analysis of the change from baseline in FEV1 indicated moderate quality of evidence $(+++)$ for the use of doxofylline versus theophylline/aminophylline, low quality of evidence $(++)$ for the use of doxofylline versus bamiphylline and very low quality of evidence $(+)$ for the use of theophylline versus aminophylline/bamiphylline and aminophylline versus bamiphylline.

The GRADE analysis of the risk of adverse events indicated high quality of evidence (++++) for the use of doxofylline versus theophylline/aminophylline and very low quality of evidence $(+)$ for the use of

a) Less effective
Safer

Less effective Less safe $\log \operatorname{RE}(95 \% \mathrm{Crl})$ b)

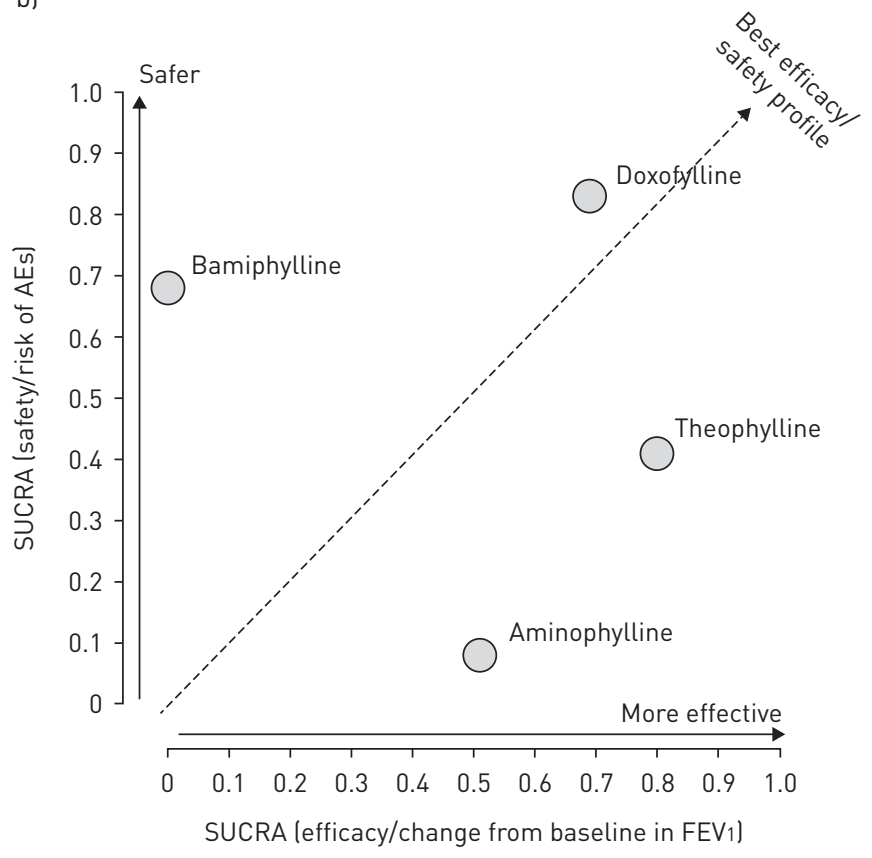

FIGURE 2 Summary findings regarding the efficacy/safety profile across xanthines in chronic obstructive pulmonary disease patients. a) Combined plot of the change from baseline in forced expiratory volume in $1 \mathrm{~s}$ (FEV 1 ) and the risk of adverse events (AEs) of specific xanthine comparisons. b) Combined efficacy/safety SUCRA (surface under the cumulative ranking curve) analysis of specific xanthines. RE: relative effect; Crl: credible interval. 
TABLE 2 Pooled analysis of adverse events extracted from the studies on xanthines administered in chronic obstructive pulmonary disease patients and ranked by frequency in agreement with European Medicines Agency guidelines [64]

\begin{tabular}{|c|c|c|c|c|c|c|c|c|c|}
\hline & \multicolumn{3}{|c|}{ Doxofylline } & \multicolumn{3}{|c|}{ Theophylline } & \multicolumn{3}{|c|}{ Aminophylline } \\
\hline & $\begin{array}{l}\text { Adverse } \\
\text { events }\end{array}$ & Rank & Statistical notes & $\begin{array}{l}\text { Adverse } \\
\text { events }\end{array}$ & Rank & Statistical notes & $\begin{array}{l}\text { Adverse } \\
\text { events }\end{array}$ & Rank & Statistical notes \\
\hline Palpitations & $3(0.77)$ & + & $\begin{array}{l}\text { Lower frequency } \\
\text { versus theophylline* } \\
\text { and aminophylline*** }\end{array}$ & $7(3.02)$ & ++ & $\begin{array}{c}\text { Higher frequency } \\
\text { versus doxofylline*, } \\
\text { lower frequency } \\
\text { versus } \\
\text { aminophylline*** }\end{array}$ & 14 (2.73) & +++ & $\begin{array}{l}\text { Higher frequency } \\
\text { versus doxofylline*** } \\
\text { or theophylline } e^{* * *}\end{array}$ \\
\hline $\begin{array}{l}\text { Gastrointestinal } \\
\text { discomfort }\end{array}$ & $3(0.77)$ & + & $\begin{array}{c}\text { No difference versus } \\
\text { theophylline (NS), } \\
\text { lower frequency } \\
\text { versus } \\
\text { aminophylline*** }\end{array}$ & $2(0.86)$ & + & $\begin{array}{l}\text { No difference versus } \\
\text { doxofylline (NS), lower } \\
\text { frequency versus } \\
\text { aminophylline*** }\end{array}$ & $\begin{array}{c}13 \\
(11.82)\end{array}$ & +++ & $\begin{array}{l}\text { Higher frequency } \\
\text { versus either } \\
\text { doxofylline*** and } \\
\text { theophylline*** }\end{array}$ \\
\hline Insomnia & $3(0.77)$ & + & $\begin{array}{l}\text { Lower frequency } \\
\text { versus theophylline** } \\
\text { and aminophylline }\end{array}$ & $11(4.74)$ & ++ & $\begin{array}{l}\text { Higher frequency } \\
\text { versus doxofylline**, } \\
\text { no difference versus } \\
\text { aminophylline (NS) }\end{array}$ & 10 (9.09) & ++ & $\begin{array}{l}\text { Higher frequency } \\
\text { versus } \\
\text { doxofylline***, no } \\
\text { difference versus } \\
\text { theophylline (NS) }\end{array}$ \\
\hline Nausea & 15 (3.84) & ++ & $\begin{array}{l}\text { Lower frequency } \\
\text { versus } \\
\text { theophylline***, no } \\
\text { difference versus } \\
\text { aminophylline (NS) }\end{array}$ & $\begin{array}{c}25 \\
(10.78)\end{array}$ & +++ & $\begin{array}{l}\text { Higher frequency } \\
\text { versus doxofylline*** } \\
\text { or aminophylline** }\end{array}$ & $1(0.91)$ & + & $\begin{array}{c}\text { No difference versus } \\
\text { doxofylline (NS), } \\
\text { lower frequency } \\
\text { versus } \\
\text { theophylline** }\end{array}$ \\
\hline Epigastralgia & 21 (5.37) & ++ & $\begin{array}{l}\text { A signal of lower } \\
\text { frequency versus } \\
\text { theophylline ( } p=0.07 \text { ), } \\
\text { no difference versus } \\
\text { aminophylline (NS) }\end{array}$ & 21 (9.05) & ++ & $\begin{array}{l}\text { A signal of higher } \\
\text { frequency versus } \\
\text { doxofylline ( } p=0.07 \text { ), } \\
\text { no difference versus } \\
\text { aminophylline (NS) }\end{array}$ & $6(5.45)$ & ++ & $\begin{array}{l}\text { No difference versus } \\
\text { doxofylline (NS) or } \\
\text { theophylline (NS) }\end{array}$ \\
\hline Headache & 12 (3.07) & ++ & $\begin{array}{l}\text { Lower frequency } \\
\text { versus theophylline**, } \\
\text { no difference versus } \\
\text { aminophylline (NS) }\end{array}$ & 20 (8.62) & ++ & $\begin{array}{l}\text { Higher frequency } \\
\text { versus doxofylline** or } \\
\text { aminophylline* }\end{array}$ & $1(0.91)$ & + & $\begin{array}{c}\text { No difference versus } \\
\text { doxofylline (NS), } \\
\text { lower frequency } \\
\text { versus theophylline* }\end{array}$ \\
\hline Arrhythmia & $2(0.51)$ & + & $\begin{array}{l}\text { No difference versus } \\
\text { theophylline (NS), a } \\
\text { signal of lower } \\
\text { frequency versus } \\
\text { aminophylline ( } p=0.06 \text { ) }\end{array}$ & $2(0.86)$ & + & $\begin{array}{l}\text { No difference versus } \\
\text { doxofylline (NS) or } \\
\text { aminophylline (NS) }\end{array}$ & $4(3.64)$ & ++ & $\begin{array}{l}\text { A signal of higher } \\
\text { frequency versus } \\
\text { doxofylline ( } p=0.06 \text { ), } \\
\text { no difference versus } \\
\text { theophylline (NS) }\end{array}$ \\
\hline Flushing & 0 (FNK) & FNK & $\mathrm{NC}$ & 0 (FNK) & FNK & $\mathrm{NC}$ & $4(3.64)$ & ++ & NC \\
\hline Tremors & $1(0.26)$ & + & $\begin{array}{l}\text { Lower frequency } \\
\text { versus theophylline* }\end{array}$ & $5(2.16)$ & ++ & $\begin{array}{l}\text { Higher frequency } \\
\text { versus doxofylline* }\end{array}$ & 0 (FNK) & FNK & NC \\
\hline Vomiting & $1(0.26)$ & + & $\begin{array}{l}\text { A signal of lower } \\
\text { frequency versus } \\
\text { theophylline }(p=0.07)\end{array}$ & $4(1.72)$ & ++ & $\begin{array}{l}\text { A signal of higher } \\
\text { frequency versus } \\
\text { doxofylline ( } p=0.07 \text { ) }\end{array}$ & 0 (FNK) & FNK & NC \\
\hline Tachycardia & 0 (FNK) & FNK & $\mathrm{NC}$ & $3(1.29)$ & ++ & $\mathrm{NC}$ & $O$ (FNK) & FNK & NC \\
\hline Anorexia & $3(0.77)$ & + & $\begin{array}{l}\text { No difference versus } \\
\text { theophylline (NS) }\end{array}$ & $3(1.29)$ & ++ & $\begin{array}{l}\text { No difference versus } \\
\text { doxofylline (NS) }\end{array}$ & 0 (FNK) & FNK & NC \\
\hline Chest pain & $2(0.51)$ & + & $\begin{array}{l}\text { No difference versus } \\
\text { theophylline (NS) }\end{array}$ & $3(1.29)$ & ++ & $\begin{array}{l}\text { No difference versus } \\
\text { doxofylline (NS) }\end{array}$ & $O$ (FNK) & FNK & NC \\
\hline Sweating & $1(0.26)$ & + & $\begin{array}{l}\text { No difference versus } \\
\text { theophylline (NS) }\end{array}$ & $3(1.29)$ & ++ & $\begin{array}{l}\text { No difference versus } \\
\text { doxofylline (NS) }\end{array}$ & 0 (FNK) & FNK & NC \\
\hline Diarrhoea & $O$ (FNK) & FNK & $\mathrm{NC}$ & $O$ (FNK) & FNK & $\mathrm{NC}$ & $1(0.91)$ & + & $\mathrm{NC}$ \\
\hline
\end{tabular}


TABLE 2 Continued

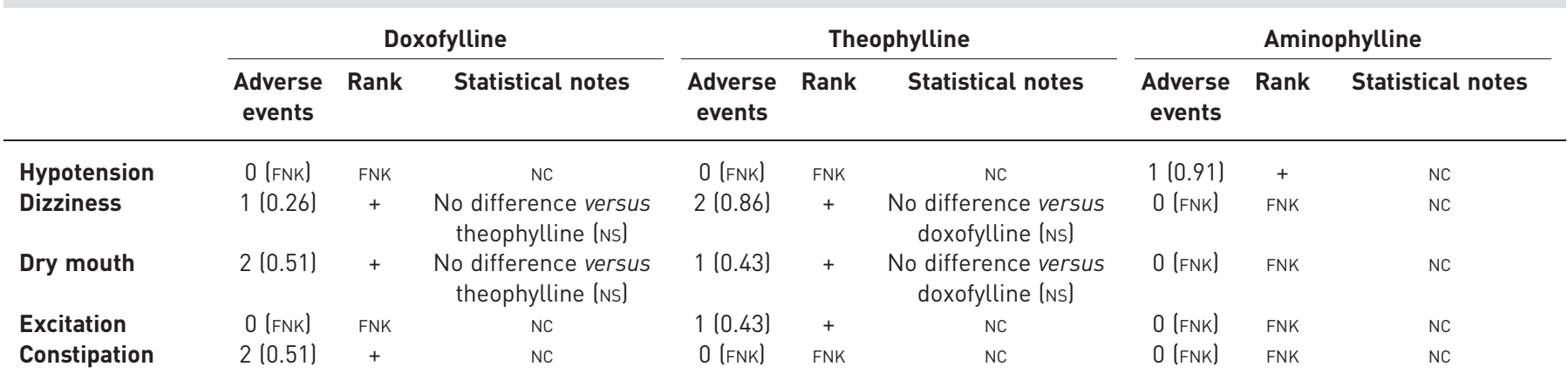

Data are presented as $\mathrm{n}$ or $\mathrm{n}(\%)$, unless otherwise stated. + : uncommon $\geqslant 1 / 1000$ to $<1 / 100 ;++$ : common $\geqslant 1 / 100$ to $<1 / 10 ;+++$ : very common $\geqslant 1 / 10$. NS: nonsignificant ( $p>0.05)$; FNK: frequency not known; NC: not calculable. ${ }^{*}: p<0.05 ;{ }^{* *}: p<0.01 ;{ }^{* * *}: p<0.001$.

doxofylline versus bamiphylline, theophylline versus aminophylline/bamiphylline and aminophylline versus bamiphylline (table 3).

\section{Discussion}

The results of our network meta-analysis demonstrate that doxofylline seems to be the best xanthine in the treatment of COPD. The SUCRA analysis has shown that doxofylline was the most effective xanthine with regard to the impact on therapeutic efficacy, followed by aminophylline and theophylline. Although no significant differences have been detected with regard to the change from baseline in FEV1 across aminophylline, doxofylline and theophylline, doxofylline and aminophylline elicited a greater beneficial impact on the improvement of dyspnoea score compared to theophylline. Moreover, doxofylline was significantly safer than both aminophylline and theophylline. The superiority of doxofylline over aminophylline, bamiphylline and theophylline has further been confirmed by the combined efficacy/safety SUCRA analysis. It is noteworthy that the meta-regression has shown that both the lung function and the total dose of xanthines administered during the studies, which can be translated as the expression of the severity of COPD, did not influence the results.

Although improving lung function is not an objective of COPD management [10], it is the primary end-point most frequently used by regulatory authorities in interpreting drug efficacy in COPD trials. A minimal clinically important difference (MCID) of $100 \mathrm{~mL}$ for pre-dose or trough FEV 1 has been proposed, based on clinical anchoring to end-points such as exacerbations, perception of dyspnoea and decline in lung function [48]. This MCID was largely achieved with aminophylline, doxofylline and theophylline when compared with bamiphylline, but not across them. The diversity of the tools used to evaluate the impact of treatments on dyspnoea makes the evaluation of the real clinical impact of the different xanthines on this symptom much more problematic. However, to rank the treatments for an outcome, we used SUCRA probabilities, which express as a percentage the efficacy of every intervention relative to an imaginary intervention that is always the best without uncertainty. Thus, large SUCRA scores might indicate a more effective intervention $[32,39]$. The high SUCRA ranking of doxofylline suggests that it is more effective than theophylline in reducing dyspnoea. Interestingly, the combined efficacy/safety SUCRA analysis documented the superiority of doxofylline over aminophylline, bamiphylline and theophylline.

The results of the present meta-analysis are not surprising considering that doxofylline should not be assumed just as another theophylline [14]. It is now well established that doxofylline possesses a distinct pharmacological profile from theophylline (table 1 and figure S4). In fact, it does not elicit any significant effect on any of the known phosphodiesterase isoforms, lacks significant adenosine receptor antagonism, does not cause a direct effect on any of the known histone deacetylase enzymes, and interacts favourably with $\beta_{2}$-adrenoceptors $[49,50]$.

Theophylline is inexpensive and widely available, and it might improve the action of another bronchodilator or even be a sufficient bronchodilator by itself in certain patients [51]. Furthermore, a potent anti-inflammatory effect at lower doses, which suggests the drug may be useful as a steroid-sparing therapy in patients with severe COPD, has been identified [1]. Nevertheless, because of its toxicity at levels close to the therapeutic range [9], theophylline is rarely used as a first-line COPD medication [1]. However, in low doses theophylline can still be considered to be an add-on therapy in those patients with severe or very severe COPD. In fact, the Spanish COPD guidelines (GesEPOC) 2017 [52] relegate it to 
TABLE 3 GRADE (grading of recommendations assessment, development and evaluation) evidence profile: impact of xanthines on change from baseline in forced expiratory volume in $1 \mathrm{~s}(\mathrm{FEV} 1)$ and risk of adverse events in chronic obstructive pulmonary disease (COPD) patients

Quality assessment: impact of xanthines in COPD

Quality

Risk of bias Inconsistency Indirectness Imprecision Other considerations

\section{Change from baseline in FEV 1}

Should doxofylline versus

theophylline be used in COPD

patients?

Should doxofylline versus

aminophylline be used in COPD

patients?

Should doxofylline versus

bamiphylline be used in COPD

patients?

Should theophylline versus aminophylline be used in COPD patients?

Should theophylline versus bamiphylline be used in COPD patients?

Should aminophylline versus bamiphylline be used in COPD patients?

\section{Risk of adverse events}

Should doxofylline versus theophylline be used in COPD patients?

Should doxofylline versus aminophylline be used in COPD patients?

Should doxofylline versus bamiphylline be used in COPD patients?

Should theophylline versus aminophylline be used in COPD patients?

Should theophylline versus bamiphylline be used in COPD patients?

Should aminophylline versus bamiphylline be used in COPD patients?

\begin{tabular}{|c|c|c|c|c|c|}
\hline Serious ${ }^{\#}$ & Not serious & Not serious & Serious ${ }^{\natural}$ & Dose response gradient & $\begin{array}{l}\oplus \oplus \oplus \bigcirc \\
\text { Moderate }\end{array}$ \\
\hline Serious ${ }^{\#}$ & Not serious & Not serious & Serious ${ }^{\natural}$ & Dose response gradient & $\begin{array}{l}\oplus \oplus \oplus \bigcirc \\
\text { Moderate }\end{array}$ \\
\hline Very serious $\#$ & Not serious & Not serious & Not serious & None & $\begin{array}{l}\oplus \oplus \bigcirc \bigcirc \\
\text { Low }\end{array}$ \\
\hline Very serious ${ }^{\#}$ & Not serious & Serious $^{+}$ & Serious ${ }^{\Uparrow}$ & $\begin{array}{l}\text { Publication bias strongly } \\
\text { suspected }\end{array}$ & $\begin{array}{l}\oplus 00 \bigcirc \\
\text { Very low }\end{array}$ \\
\hline Very serious ${ }^{\#}$ & Not serious & Very serious ${ }^{f}$ & Not serious & $\begin{array}{l}\text { Very strong association, } \\
\text { publication bias strongly } \\
\text { suspected }\end{array}$ & $\begin{array}{l}\oplus \bigcirc \bigcirc \bigcirc \\
\text { Very low }\end{array}$ \\
\hline Very serious ${ }^{\#}$ & Not serious & Very serious ${ }^{f}$ & Not serious & $\begin{array}{c}\text { Very strong association, } \\
\text { publication bias strongly } \\
\text { suspected }\end{array}$ & $\begin{array}{l}\oplus \bigcirc \bigcirc \bigcirc \\
\text { Very low }\end{array}$ \\
\hline Serious $\#$ & Not serious & Not serious & Not serious & $\begin{array}{l}\text { Strong association, dose } \\
\text { response gradient }\end{array}$ & $\begin{array}{l}\oplus \oplus \oplus \oplus \\
\text { High }\end{array}$ \\
\hline Serious ${ }^{\#}$ & Not serious & Not serious & Not serious & $\begin{array}{l}\text { Very strong association, dose } \\
\text { response gradient }\end{array}$ & $\begin{array}{l}\oplus \oplus \oplus \oplus \\
\text { High }\end{array}$ \\
\hline Very serious $\#$ & Not serious & Serious $^{+}$ & Serious" & $\begin{array}{l}\text { Publication bias strongly } \\
\text { suspected }\end{array}$ & $\begin{array}{l}\oplus 00 \bigcirc \\
\text { Very low }\end{array}$ \\
\hline Very serious $\#$ & Not serious & Serious $^{+}$ & Serious $ף$ & $\begin{array}{l}\text { Publication bias strongly } \\
\text { suspected }\end{array}$ & $\begin{array}{l}\oplus 000 \\
\text { Very low }\end{array}$ \\
\hline Very serious ${ }^{\#}$ & Not serious & Very serious ${ }^{f}$ & Serious ${ }^{\pi}$ & $\begin{array}{l}\text { Publication bias strongly } \\
\text { suspected }\end{array}$ & $\begin{array}{l}\oplus \circ 0 \bigcirc \\
\text { Very low }\end{array}$ \\
\hline Very serious ${ }^{\#}$ & Not serious & Very serious $^{f}$ & Serious" & $\begin{array}{l}\text { Publication bias strongly } \\
\text { suspected }\end{array}$ & $\begin{array}{l}\oplus \bigcirc \bigcirc \bigcirc \\
\text { Very Low }\end{array}$ \\
\hline
\end{tabular}

GRADE working group grades of evidence: high quality (we are very confident that the true effect lies close to that of the estimate of the effect); moderate quality (we are moderately confident in the effect estimate; the true effect is likely to be close to the estimate of the effect, but there is a possibility that it is substantially different); low quality (our confidence in the effect estimate is limited; the true effect may be substantially different from the estimate of the effect); very low quality (we have very little confidence in the effect estimate, the true effect is likely to be substantially different from the estimate of effect). \#: confirmed by Jadad score values; " ${ }^{\text {: }}$ credible intervals cross the threshold between recommending and not recommending treatment; ${ }^{+}$: drugs tested head-to-head in a small population; ${ }^{\S}$ : data from direct comparison of small studies; ${ }^{f}$ : drugs not tested head-to-head; ${ }^{\# \#}$ : data from indirect comparison of small studies.

third-line treatment, mainly in high-risk patients who continue to be dyspnoeic following dual bronchodilator therapy. In addition, the French-Language Respiratory Society (Société de Pneumologie de Langue Française) proposes its use for patients with dyspnoea on long-acting bronchodilators [53].

Given the pharmacological profile of doxofylline $[49,50]$; its significant anti-inflammatory activity that can result in significant steroid sparing activity, as documented at least in both an allergic and a nonallergic murine model of lung inflammation [54]; its documented clinical activity [12-14]; and, above all, the results of the present meta-analysis, there is a clear need to understand what is the room in the treatment of COPD for a xanthine that induces the same, if not even better, therapeutic effects of theophylline but with a totally different safety profile. Specifically, the rate of study withdrawal due to adverse events such 
as dyspepsia, epigastralgia, nausea and palpitation was approximately four-fold higher in COPD patients treated with theophylline than in those treated with doxofylline.

Meta-analysis is an analytical technique designed to summarise the results of multiple studies in order to effectively increase sample size and provide valid pooled effect estimates [55]. It can be considered a systematic study of the currently available studies undertaken to answer specific questions or hypotheses [56]. In this regard, meta-analyses are mainly focused on questions ideally intended to solve clinical problems in agreement with the PICO strategy [17, 57]. Actually, the network meta-analytical approach is an extension of traditional pairwise meta-analysis. It represents a novel and effective statistical method that permits to incorporate clinical evidence from both direct and indirect treatment comparisons in a complete network of trials in order to assess the efficacy and risk of adverse events of multiple interventions [58]. Furthermore, the network meta-analytical approach permits to report the treatment rankings via the SUCRA method, a simple numerical summary to supplement the graphical display [59]. As already mentioned, this method facilitates the interpretation of the effect estimates resulting from indirect/mixed comparisons, and it can be important for clinicians who wish to know what is the best treatment for certain clinical conditions [58].

Despite the several advantages that a network meta-analysis can provide with respect to the real impact of different xanthines in the treatment of stable COPD patients, this quantitative synthesis has also some limitations, which mainly stem from the quality of reported data.

First of all, we must point out that xanthines have mostly been compared to placebo rather than active agents; trials were relatively small; and most studies are old, i.e. performed at a time when none of the current reference inhaled treatments were available. Clearly, this means that the results of our meta-analysis do not allow the placement of xanthines within the global COPD therapeutic framework. However, theophylline, being cheap and widely available, remains one of the most widely prescribed drugs for COPD treatment in developing countries [60]. Doxofylline, which presently is used in some regions of the world, can offer an alternative safer treatment, because of the lower risk of adverse events when compared with conventional "high-dose" theophylline, making blood monitoring unnecessary.

Another important limitation of the present meta-analysis relates to the lack of information on important outcomes such as exacerbations. Xanthines are considered to have no role in the acute exacerbation of COPD because a lack of solid information and, in effect, the last European Respiratory Society/American Thoracic Society document on prevention of COPD exacerbations did not mention xanthines [61]. Only two studies have compared oral theophylline with placebo to explore its capacity in reducing the frequency of COPD exacerbations, with contrasting results [62, 63]. No study has evaluated the impact of aminophylline, bamiphylline and doxofylline in reducing the frequency of COPD exacerbations.

Furthermore, it was impossible to establish whether there is any difference between slow- and rapid-release preparations of aminophylline or theophylline when compared with doxofylline. In addition, data in the literature did not allow us to evaluate the impact of duration of exposure to medications and that of comorbid conditions on our results. The adverse events relative to the concomitant medications remain unknown, but we must point out that the total dose of xanthines administered during the studies and the route of administration have influenced our scores.

Despite these limitations, we believe that this network meta-analysis provides valuable information on the efficacy and safety of doxofylline in people with stable COPD. It is our opinion that the use of an orally active drug that is safe, effective and relatively inexpensive, as doxofylline is, must be encouraged, particularly for those COPD patients who find inhalers difficult to use or who do not get adequate control from other pharmacological classes. In any case, we would encourage further randomised clinical trials of doxofylline to investigate the use of this drug to reduce acute exacerbations and hospitalisations due to COPD as an alternative to more expensive combined therapies, and certainly as an alternative to theophylline.

Conflict of interest: M. Cazzola reports personal fees from ABC Farmaceutici, outside the submitted work, and received personal fees to perform the meta-analysis and write the article. L. Calzetta reports personal fees from $A B C$ Farmaceutici, during the conduct of the study, and received personal fees to perform the meta-analysis and write the article. M.G. Matera reports personal fees from ABC Farmaceutici, outside the submitted work. She is also a consultant at $\mathrm{ABC}$ Farmaceutici and was supported to write the article.

Support statement: $\mathrm{ABC}$ Farmaceutici that manufactures and sells medicinal products containing doxofylline provided the funds to perform the meta-analysis and write the article. Funding information for this article has been deposited with the Crossref Funder Registry.

\section{References}

1 Barnes PJ. Theophylline. Am J Respir Crit Care Med 2013; 188: 901-906. 
2 Molfino NA, Zhang P. A meta-analysis on the efficacy of oral theophylline in patients with stable COPD. Int $J$ Chron Obstruct Pulmon Dis 2006; 1: 261-266.

3 Taylor DR, Buick B, Kinney C, et al. The efficacy of orally administered theophylline, inhaled salbutamol, and a combination of the two as chronic therapy in the management of chronic bronchitis with reversible air-flow obstruction. Am Rev Respir Dis 1985; 131: 747-751.

4 Murciano D, Auclair MH, Pariente R, et al. A randomized, controlled trial of theophylline in patients with severe chronic obstructive pulmonary disease. N Engl J Med 1989; 320: 1521-1525.

5 Chrystyn H, Mulley BA, Peake MD. Dose response relation to oral theophylline in severe chronic obstructive airways disease. $B M J 1988 ; 297$ : 1506-1510.

6 Barnes PJ. Theophylline. Pharmaceuticals 2010; 3: 725-747.

7 Kirsten DK, Wegner RE, Jörres RA, et al. Effects of theophylline withdrawal in severe chronic obstructive pulmonary disease. Chest 1993; 104: 1101-1107.

8 McIvor RA, Tunks M, Todd DC. COPD. BMJ Clin Evid 2011; 2011: 1502.

9 Miravitlles M, Vogelmeier C, Roche N, et al. A review of national guidelines for management of COPD in Europe. Eur Respir J 2016; 47: 625-637.

10 Spina D, Page CP. Xanthines and phosphodiesterase inhibitors. Handb Exp Pharmacol 2017; 237: 63-91.

11 Horita N, Miyazawa N, Kojima R, et al. Chronic use of theophylline and mortality in chronic obstructive pulmonary disease: a meta-analysis. Arch Bronconeumol 2016; 52: 233-238.

12 Shukla D, Chakraborty S, Singh S, et al. Doxofylline: a promising methylxanthine derivative for the treatment of asthma and chronic obstructive pulmonary disease. Expert Opin Pharmacother 2009; 10: 2343-2356.

13 Page CP. Doxofylline: a 'novofylline'. Pulm Pharmacol Ther 2010; 23: 231-234.

14 Matera MG, Page C, Cazzola M. Doxofylline is not just another theophylline! Int J Chron Obstruct Pulmon Dis 2017; 12: 3487-3493.

15 Moher D, Liberati A, Tetzlaff J, et al. Preferred reporting items for systematic reviews and meta-analyses: the PRISMA statement. Open Med 2009; 3: e123-e130.

16 Moher D, Shamseer L, Clarke M, et al. Preferred reporting items for systematic review and meta-analysis protocols (PRISMA-P) 2015 statement. Syst Rev 2015; 4: 1.

17 Schardt C, Adams MB, Owens T, et al. Utilization of the PICO framework to improve searching PubMed for clinical questions. BMC Med Inform Decis Mak 2007; 7: 16.

18 Calzetta L, Rogliani P, Matera MG, et al. A systematic review with meta-analysis of dual bronchodilation with LAMA/LABA for the treatment of stable COPD. Chest 2016; 149: 1181-1196.

19 Cazzola M, Rogliani P, Calzetta L, et al. Impact of mucolytic agents on COPD exacerbations: a pair-wise and network meta-analysis. COPD 2017; 14: 552-563.

20 Cazzola M, Calzetta L, Rogliani P, et al. Tiotropium formulations and safety: a network meta-analysis. Ther Adv Drug Saf 2017; 8: 17-30.

21 Guyatt G, Oxman AD, Akl EA, et al. GRADE guidelines: 1. Introduction-GRADE evidence profiles and summary of findings tables. J Clin Epidemiol 2011; 64: 383-394.

22 Pedder H, Sarri G, Keeney E, et al. Data extraction for complex meta-analysis (DECiMAL) guide. Syst Rev 2016; 5 : 212.

23 Bossi R, Berni F. Double blind multicenter trial on efficacy and tolerability of doxofylline vs aminophylline in patients with chronic airway obstruction and reversible bronchospasm. Ital J Chest Dis 1989; 43: 355-360.

24 Melillo G, Balazano G, Jodice F, et al. Treatment of reversible chronic obstruction with doxofylline compared with slow-release theophylline: a double-blind, randomized, multicentre trial. Int J Clin Pharmacol Res 1989; 9: 396-405.

25 Santra CK. Treatment of moderate chronic obstructive pulmonary disease (stable) with doxofylline compared with slow release theophylline - a multicentre trial. J Indian Med Assoc 2008; 106: 791-792.

26 Wu S-L, Wang S-Z. Observation of doxofylline in treatment of acute exacerbation chronic obstructive pulmonary disease. Med J West China 2011; 5: 065.

27 Liu JW. Influence of doxofylline on inflammatory mediators in chronic obstructive pulmonary disease. Mod J Integr Tradit Chin West Med 2011; 20: 665-666.

28 Wang T, Luo G, Hu Y, et al. Comparative study on the efficacy of tiotropium bromide inhalation and oral doxofylline treatment of moderate to severe stable chronic obstructive pulmonary disease. J Huazhong Univ Sci Technolog Med Sci 2011; 31: 614-618.

29 Cipri A, Pozzar F, Dini FL. Alterazioni del ritmo cardiaco in pazienti con broncopneumopatia cronica ostruttiva: effetto di differenti farmaci metilxantinici. [Cardiac rhythm disturbances in patients with chronic obstructive pulmonary disease: effects of different methylxanthine drugs]. Minerva Cardioangiol 1992; 40: 31-39.

30 Marino O, Silvi E, Lilli A, et al. Studio comparativo tra doxofillina e trofilline anidra a rilascio protratto in soggetti affetti da broncopneumopaita cronica ostruttiva [Comparative study of doxofylline and anhydrous prolonged-release theophylline in subjects with chronic obstructive pulmonary disease]. L'uomo e la Medicina 1988; 4: 33-37.

31 Calzetta L, Rogliani P, Ora J, et al. LABA/LAMA combination in COPD: a meta-analysis on the duration of treatment. Eur Respir Rev 2017; 26: 160043.

32 Lu G, Ades AE. Assessing evidence inconsistency in mixed treatment comparisons. J Am Stat Assoc 2006; 101: 447-459.

33 Spiegelhalter DJ, Abrams KR, Myles JP. Bayesian Approaches to Clinical Trials and Health-Care Evaluation. Chichester, John Wiley \& Sons, 2004.

34 van Valkenhoef G, Lu G, de Brock B, et al. Automating network meta-analysis. Res Synth Methods 2012; 3: 285-299.

35 Valkenhoef G, Dias S, Ades AE, et al. Automated generation of node-splitting models for assessment of inconsistency in network meta-analysis. Res Synth Methods 2016; 7: 80-93.

36 Dias S, Welton NJ, Sutton AJ, et al. Evidence synthesis for decision making 4: inconsistency in networks of evidence based on randomized controlled trials. Med Decis Making 2013; 33: 641-656.

37 Richy F, Scarpignato C, Lanas A, et al. Efficacy and safety of piroxicam revisited. A global meta-analysis of randomised clinical trials. Pharmacol Res 2009; 60: 254-263. 
38 Cazzola M, Calzetta L, Rogliani P, et al. Tiotropium formulations and safety: a network meta-analysis. Ther Adv Drug Saf 2017; 8: 17-30.

39 Wallace BC, Dahabreh IJ, Trikalinos TA, et al. Closing the gap between methodologists and end-users: R as a computational back-end. J Stat Softw 2012; 49 https://doi.org/10.18637/jss.v049.i05.

40 Sullivan KM, Dean A, Soe MM. OpenEpi: a web-based epidemiologic and statistical calculator for public health. Public Health Rep 2009; 124: 471-474.

41 Lal D, Manocha S, Ray A, et al. Comparative study of the efficacy and safety of theophylline and doxofylline in patients with bronchial asthma and chronic obstructive pulmonary disease. J Basic Clin Physiol Pharmacol 2015; 26: 443-451.

42 Akram MF, Nasiruddin M, Ahmad Z, et al. Doxofylline and theophylline: a comparative clinical study. J Clin Diagn Res 2012; 6: 1681-1684.

43 Orefice U, Struzzo PL, Dini FL, et al. A randomized placebo-controlled clinical trial to compare efficacy and safety of docofylline and bamifylline in COPD patients. Clinica e Terapia 1991; 2: 109-113.

44 De Benedetto F, Fini G, Dini FL, et al. Cardio-respiratory effects of intravenous infusion of xanthine derivatives: gas exchange and dynamic electrocardiogram monitoring in COPD patients. Ital J Chest Dis 1991; 45: 353-357.

45 Mutti L, Castagneto B, Occhionero L, et al. Variations in a specific bronchial reactivity elicited by methacholine in chronic bronchitis patients treated with doxofylline. Double blind cross-over study versus theophylline slow release. Acta Toxicologica et Therapeutica 1991; 12: 269-276.

46 Panuccio P, Viroli F. A randomised clinical study comparing doxofylline and bamiphilline in chronic obstructive pulmonary disease. Int J Drugs Ther 1989; 6: 1-4.

47 Fontana G, Cresci F, Lo Sapio P, et al. Serum theophylline concentrations and pulmonary function tests after administration of two sustained-release formulations containing theophylline in patients affected by chronic obstructive lung disease. Int J Clin Pharmacol Res 1987; 7: 351-356.

48 Jones PW, Beeh KM, Chapman KR, et al. Minimal clinically important differences in pharmacological trials. Am J Respir Crit Care Med 2014; 189: 250-255.

49 van Mastbergen J, Jolas T, Allegra L, et al. The mechanism of action of doxofylline is unrelated to HDAC inhibition, PDE inhibition or adenosine receptor antagonism. Pulm Pharmacol Ther 2012; 25: 55-61.

50 Zhang $\mathrm{Y}$, Zeng $\mathrm{K}$, Wang $\mathrm{J}$, et al. Identifying the antiasthmatic target of doxofylline using immobilized $\beta 2$-adrenoceptor based high-performance affinity chromatography and site directed molecular docking. $J \mathrm{Mol}$ Recognit 2016; 29: 492-498.

51 Grouse L. Selective polypharmacy for chronic obstructive pulmonary disease. J Thorac Dis 2015; 7: E16-E18.

52 Miravitlles M, Soler-Cataluña JJ, Calle M, et al. Spanish guidelines for management of chronic obstructive pulmonary disease (GesEPOC) 2017. Pharmacological treatment of stable phase. Arch Bronconeumol 2017; 53: 324-335.

53 Zysman M, Chabot F, Housset B, et al. Pharmacological treatment optimisation for stable COPD: an endless story? Proposals from the Société de Pneumologie de Langue Francaise. Eur Respir J 2017; 50 : 1701250.

54 Riffo-Vasquez Y, Venkatasamy R, Page CP. Steroid sparing effects of doxofylline. Pulm Pharmacol Ther 2018; 48 https://doi.org/10.1016/j.pupt.2017.10.008

55 Greco T, Zangrillo A, Biondi-Zoccai G, et al. Meta-analysis: pitfalls and hints. Heart Lung Vessel 2013; 5: 219-225.

56 Noble JH Jr. Meta-analysis: methods, strengths, weaknesses, and political uses. J Lab Clin Med 2006; 147: 7-20.

57 Mattos CT, Ruellas AC. Systematic review and meta-analysis: what are the implications in the clinical practice? Dental Press J Orthod 2015; 20: 17-19.

58 Catalá-López F, Tobías A, Cameron C, et al. Network meta-analysis for comparing treatment effects of multiple interventions: an introduction. Rheumatol Int 2014; 34: 1489-1496.

59 Salanti G, Ades AE, Ioannidis JP. Graphical methods and numerical summaries for presenting results from multiple-treatment meta-analysis: an overview and tutorial. J Clin Epidemiol 2011; 64: 163-171.

60 Ma YJ, Jiang DQ, Meng JX, et al. Theophylline: a review of population pharmacokinetic analyses. J Clin Pharm Ther 2016; 41: 594-601.

61 Wedzicha JA, Calverley PMA, Albert RK, et al. Prevention of COPD exacerbations: a European Respiratory Society/American Thoracic Society guideline. Eur Respir J 2017; 50: 1602265.

62 Rossi A, Kristufek P, Levine BE, et al. Comparison of the efficacy, tolerability, and safety of formoterol dry powder and oral, slow-release theophylline in the treatment of COPD. Chest 2002; 121: 1058-1069.

63 Zhou Y, Wang X, Zeng X, et al. Positive benefits of theophylline in a randomized, double-blind, parallel-group, placebo-controlled study of low-dose, slow-release theophylline in the treatment of COPD for 1 year. Respirology 2006; 11: 603-610.

64 European Commission. A Guideline on Summary of Product Characteristics (SmPC). 2009. http://ec.europa.eu/ health//sites/health/files/files/eudralex/vol-2/c/smpc_guideline_rev2_en.pdf Date last accessed: June 22, 2017. 